\title{
List of plates
}

1.1 A woman sitting outside her tsunami-destroyed house, Kallady (Batticaloa) (2005). Image: Rebecca Walker page 10

2.1 Mother's meeting, Batticaloa (2006). Image: Rebecca Walker 53

6.1 Returning to the sea, Kallady (Batticaloa) (2005). Image: Rebecca Walker 146

7.1 Children playing in the sea, Batticaloa (2005). Image: Rebecca Walker 166 
Rebecca Walker - 9781526130754 Downloaded from manchesterhive.com at 04/26/2023 06:20:47AM via free access 